\title{
Material microstructure affected machining: a review
}

\author{
Zhipeng Pan, Yixuan Feng, and Steven Y. Liang* \\ Woodruff School of Mechanical Engineering, Georgia Institute of Technology, Atlanta, GA 30332, USA
}

Received 8 March 2017 / Accepted 6 April 2017

\begin{abstract}
The machining induced material microstructure evolution path is determined from the temperature and mechanical loading history. Inversely, the machining forces and machined part surface integrity are dependent on the material microstructure attributes. Most of the previous research work with a microstructure consideration in machining stays largely on the experimental observation stage. A comprehensive thermal-mechanical-microstructure coupled machining process modeling framework is still missing. This paper reviews the recent research work on the material microstructure evolution in the context of machining components. The material microstructure property change on the workpiece material in the machining process are analyzed. The effects of material microstructure evolution on workpiece mechanical properties and surface integrity are investigated. It is concluded that a physical based material microstructure affected machining model is needed for the machining process optimization.
\end{abstract}

Key words: Machining, Microstructure, Phase transformation, Grain size, Modeling

\section{Introduction}

The precision machining has long been focused on the machined part geometrical consideration, such as dimensional accuracy and surface roughness. The machined part dimensional accuracy is strongly influenced by the tool wear and tool deflection [1-3]. The surface roughness is a function of process parameters, such as cutting speed, feed rate, and tool geometry (edge radius, rake angle). With the rapid development of precision machining technology, the manufacturing end-product functionality requires the precision machining capability beyond machined part geometrical properties. Other aspects of the machining end-product, including the surface physical properties, metallurgical, chemical and biological characterizations are also part of the precision machining requirement [4-7]. The surface residual stress profile could significantly influence the workpiece fatigue life and corrosion resistance. In additional to the mechanical states, the material microstructure attributes are closely related to the surface functionalities [8]. For example, the surface micro-hardness is dominated by the grain size and phase composition for multiphase material. Other microstructure properties of the machined surface include the plastic deformation induced dislocation density, phase transformation, micro-cracks and intergranualar attack [9]. In order to fully describe the precision machining process, the microstructure consideration is required. Compared with the traditional framework which only includes the thermal

*e-mail: steven.1iang@me.gatech.edu and mechanical considerations, the microstructure based machining process model could provide a more in-depth understanding of the mechanical, thermal and microstructural interactions.

The microstructure consideration in the machining process covers phase transformation, dynamic recrystallization, grain morphology and dislocation density. The material microstructure evolution in the machining process is a combined effect from the thermal-mechanical interactions. For example, the phase transformation is dependent on the temperature history, grain growth is determined by the strain, strain rate and temperature effect. In addition, the material microstructure properties would inversely affect the material mechanical properties and heat generation in the machining processes. Therefore, a thermal-mechanical-microstructural coupled framework would be more desirable for the machining process description. The material microstructure evolution in the machining process could be lead to the undesirable direction, such as increased grain size on the machined surface, or undesirable phase transformation effect. In order to avoid this, a comprehensive machining process design process would be required, which takes the machining process parameters, machine tool configuration and workpiece material properties into consideration. The current work aims to bring out a computational framework to assist the machining process design and optimization, which outputs the machined end-product microstructure states related surface integrity properties. The model would need a material microstructure structural evolution model, explicit correlation of the material mechanical 
Table 1. Previous research on white layer formation in machining.

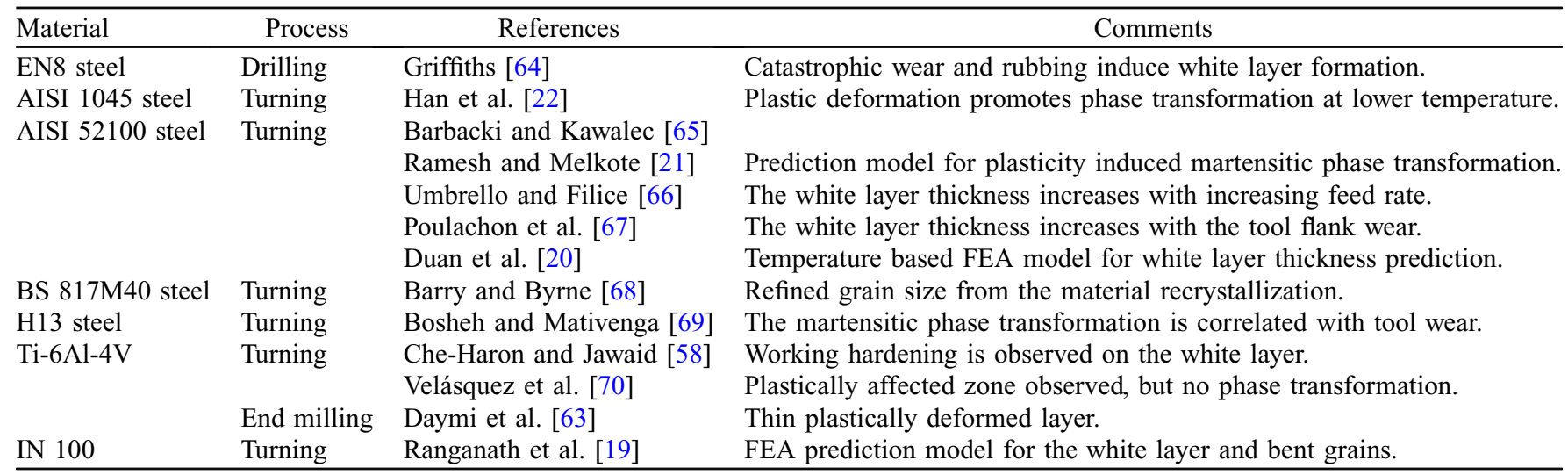

properties with material microstructural states. This paper, for the first time, concludes from the current state of the art research in machining with a consideration of the material microstructure properties, brings out the material microstructure affected machining framework.

\section{Machining induced microstructure evolution}

In the manufacturing processes, such as hot forging, laser assisted melting and friction stir welding, the material microstructure would typically have considerable change due to the high temperature effect [10-12]. With the development of high speed machining equipment, the increased cutting speed could elevate the machining temperature where material microstructure is unstable. In a traditional manufacturing process, the material microstructural evolution path is mainly dependent on the temperature history. In the machining process, the server plastic deformation (large strain, high strain rate) could also help to promote the material microstructure evolution. The material microstructure evolution mainly occurs in the primary shear zone and machined workpiece surface.

The microstructure change on the machined surface typically manifest as the white layer. In the machining process, the generation of white layer mainly attributes to the two mechanisms: the phase transformation from rapid heating and quenching, the homogenous structure or ultrafine grain structure from the server plastic deformation. A list of some selected research work on the white layer is shown in Table 1. The white layer in the hard turning of AISI 52100 steel alloys has been reported by the Chou and Evans [13]. In the white layer, improved material microhardness is observed due to possible strain hardening effect. In the laser assisted milling of Al 2024 alloy, up to around $5 \mu \mathrm{m}$ thick heat affected zone layer is observed, where a-liquid phases are generated [14], shown in Figure 1. High residual stress concentration and reduced fatigue life on the heat affected zone are observed. In the high speed hard turning of hardened steels with ceramic cutting tool, refined grain structure and white layer is observed on the machined surface up to $2 \mu \mathrm{m}$ depth into the workpiece. Compared with the ceramic cutting insert, less significant

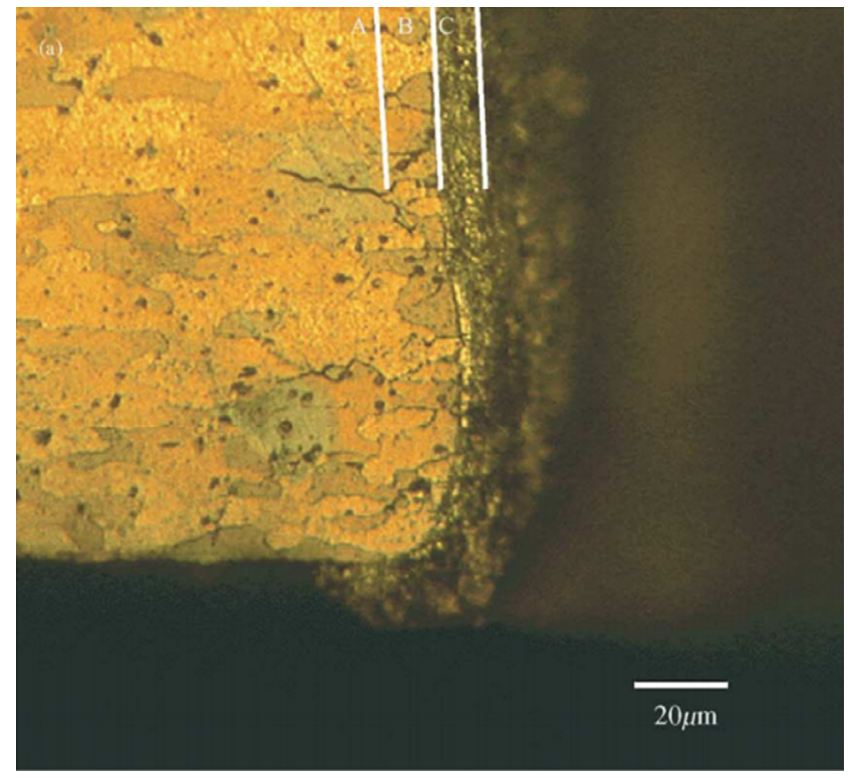

Figure 1. The heat affected zone of the aluminum alloy after the laser assisted milling process, where A is the unaffected area, B indicates the elongated grain structure region, $\mathrm{C}$ shows the refined $\alpha$-grain structure [14].

microstructure alteration is found when machining with PCBN tool, as reported by EI-Wardany et al. [15]. The micromachining, the material microstructure has strong influence on the end product qualify. The roughness of the machining surface is a dominated by surface layer grain size. More than three times better surface roughness was reported by Popov et al. [16] in the milling of ultra-fine grain aluminum. In the high speed milling of AISI H12 steel, significant microstructure and microhardness changes are found [17]. Also the effect of different milling conditions on the microstructure are investigated, as shown in Figure 2. Extensive grain refinement and strain induced martensitic phase transformation near the machined surface in finish turning of 304L steel are reported by Ghosh and Kain [18], as shown in Figure 3. The work hardened layer on the surface could help to increase the susceptibility to stress corrosion crack of the machined surface. 
(a)

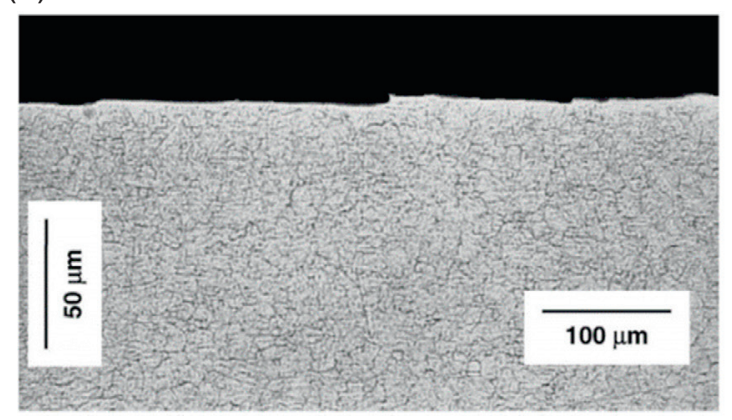

(b)

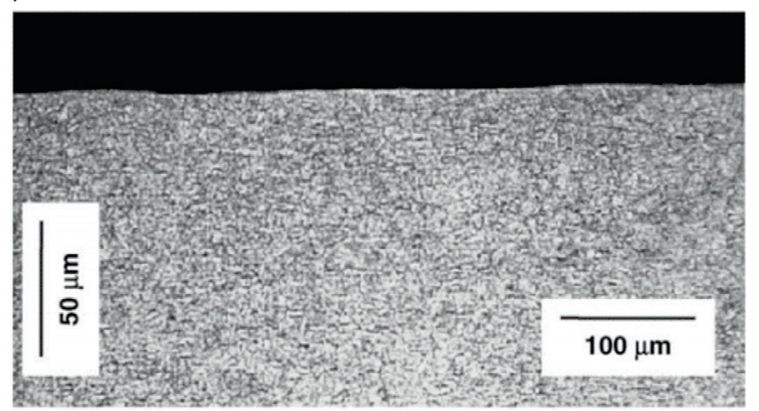

Figure 2. The microstructure of the AISI H13 steel of the machined workpiece at cutting speed of $300 \mathrm{~m} / \mathrm{min}$, feed rate $=0.1 \mathrm{~mm} / \mathrm{tooth}$, axial depth of cut $=0.2 \mathrm{~mm}$, (a) at cutting direction of $0^{\circ}$ (b) cutting direction of $60^{\circ}$ [17].

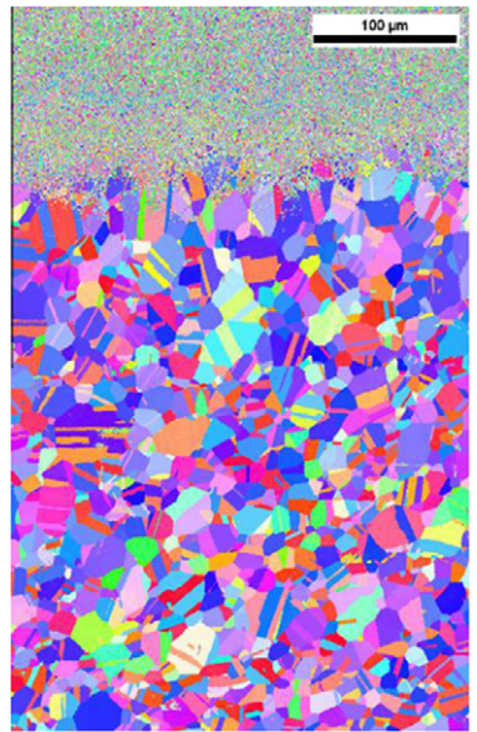

[001]

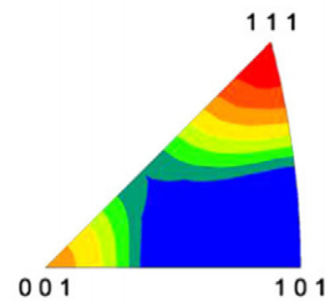

Figure 3. EBSD image showing around $150 \mu \mathrm{m}$ thick layer grain refinement (less than $0.5 \mu \mathrm{m}$ ) in the machined surface [18].

Besides the observation on the white layer formation purely from experimental study, both empirical and physical based models have been proposed to predict the white layer generation after machining. A finite element based model is developed by Ranganth et al. [19] to calculate the plastic strain, which is believed to be the cause of white layer generation on the machined surface of Inconel 100 alloy. The temperature effect on the white layer generation is largely ignored. Duan et al. [20] argued that, the phase transformation is the dominating factor in white layer generation. A pure temperature based phase transformation model is used for the white layer thickness prediction. Ramesh and Melkote [21] developed a model that incorporates the strain, stress and temperature effect on the white layer generation. Similar research is done by Han et al. [22] in turning of AISI 1045 steel. From a more physics based ground, an analytical model is proposed by Chou and Song [23] to calculate the white layer thickness in the orthogonal turning of hardened steel. More specifically, Umbrello et al. [24] called the phase transformation layer as the dark layer on the machining surface of AISI 51200 steel. A finite element analysis (FEA) model is developed for the prediction of both white layer and dark layer on the machined surface.

The shear zone, where large plastic deformation occurs, typically there would be considerable microstructure change. Another factor that influences the microstructure change in the primary shear zone is the high temperature. Different from the tool workpiece interface, where the heat is generated mainly from the friction effect, the plastic energy to heat transformation in the shear zone is the dominating factor. Another characteristics of the shear zone is the large strain and high strain rate. A list of some representative previous research work on the material microstructure change in the shear zone is provided in Table 2. Wan et al. [25] reported that, with the increasing cutting speed, the shear zone would go through deformed bands to transformed bands in the machining of titanium alloy. The Martensitic phase transformation from $\alpha$ phase is triggered by the high temperature, as shown in Figure 4. Similar report is also provided by Shivpuri et al. [26]. The phase transformation is one of the dominating factors that influence the chip morphology in the machining of multiphase material. Though extensive experimental studies have been conducted to investigate the phase transformation on chip formation, few prediction model has been developed. In the micro milling process, the workpiece material microstructure properties will strongly influence the minimum chip thickness and machined surface roughness, as reported by Vogler et al. [27]. Interrupted chip formation occurs when the milling tool passes through the grain boundaries for multiphase materials. Considerable material recrystallization has been reported by Pan et al. [28] in the orthogonal turning of Ti-6Al-4V. The grain size refinement is also found in the shear zone as an effect of the high temperature, large strain and high strain rate.

\section{Microstructure effect on machining}

\subsection{Material microstructure effects on machining forces}

The material microstructure variation could result in significant flow stress change. For the most of conventional machining process, the material could be treated as homogeneous where material microstructure variation are neglected. 
Table 2. Related research work on the microstructure change in the shear zone.

\begin{tabular}{lll}
\hline Material & \multicolumn{1}{c}{ References } & \multicolumn{1}{c}{ Comments } \\
\hline Amour steel & Derep [71] & Phase transformation occurs in the adiabatic shear zone observed. \\
AISI 1045 steel & Duan and Zhang [72] & Plastic shear, reorientation and elongation of the martensitic laths. \\
Ti-6Al-4V & Shivpuri et al. [26] & Phase transformation occurs in the shear zone. \\
& Wan et al. [25] & Microstructure evolution in shear zone depends on cutting speed. \\
& Bayoumi and Xie [73] & Non-diffusion phase transformation in shear localized chips. \\
& Velásquez et al. [74] & Deformation shear bands occurs, but no phase transformation observed. \\
Al-7075 & Ye et al. [75] & A momentum diffusion based-model is proposed to predict chip segmentation. \\
Al-6061-T6 & Campbell et al.[76] & Recrystallized equiaxed grains within the shear bands. \\
\hline
\end{tabular}

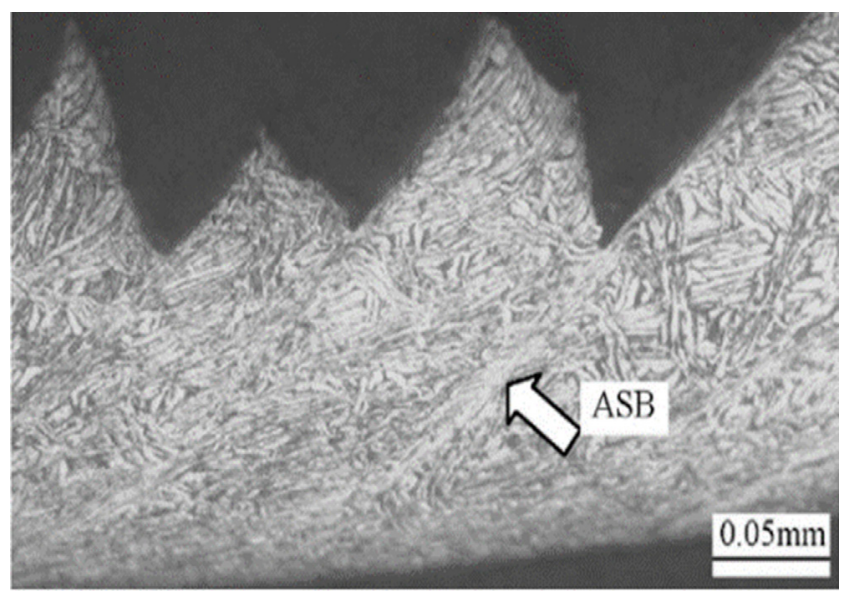

Figure 4. The martensitic transformation in the adiabatic shear bands (ASB) in turning of Ti-6Al-4V at rake angle of $10^{\circ}$, cutting speed $30.2 \mathrm{~m} / \mathrm{min}$, depth of cut $0.3 \mathrm{~mm}$, feed rate $0.21 \mathrm{~mm} / \mathrm{rev}$ [25].

However, in the micromachining processes, the machining depth of cut could be smaller than the grain size of the material. Many materials, such as steels or titanium alloys do not exhibit good homogeneity at the microscale. The grain orientation of $\mathrm{SiC}$ whiskers with respect to the cutting directions would strongly influence the cutting force in the orthogonal turning process, as reported by Yuan et al. [29]. The cutting force also varies with the grain boundaries in the machining of aluminum alloys [30]. Chou [31] reported increased tool life in the turning of fine microstructure steels compared with conventional steels. A microstructure based machining force prediction model is proposed by Chuzhoy et al. [32] to consider the different phase compositions in the turning of ductile irons. The smaller grain size of the material will result in both higher frequency and magnitude of the machining forces. Vogler et al. [33] also developed a statistic model to incorporate the microstructure consideration in the micro-end milling of iron. With a grain size evolution consideration in the shear zone, a more accurate force prediction model is developed for the machining of Ti-6Al-4V material [28].

In the machining process, the machining force mainly comes from the plastic deformation stress in the primary shear zone, the friction stress between the tool and workpiece. In most cases, when the cutting tool nose radius is smaller enough compared with the depth of cut, the plastic deformation dominates. Server plastic deformation in the shear zone

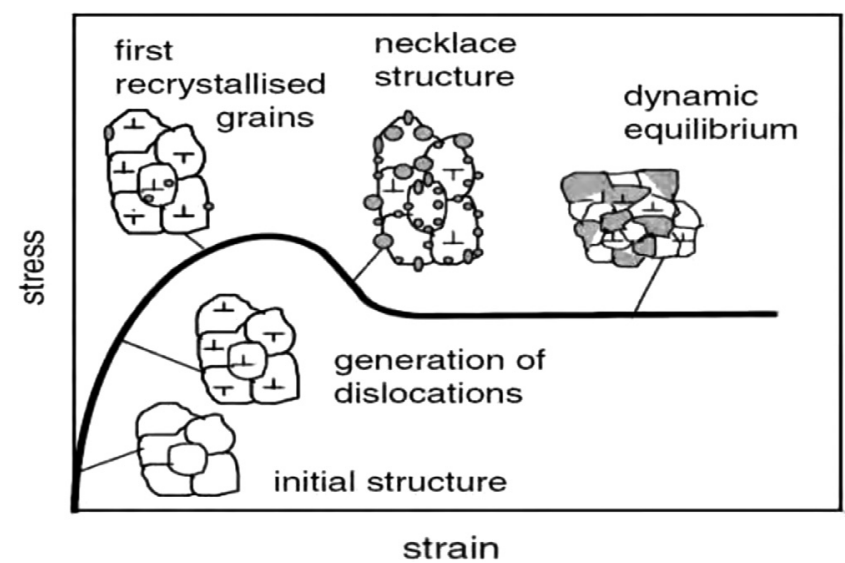

Figure 5. The influence of material microstructure on the material flow stress [38].

would generate considerable heat. Combined with the large strain, high strain rate, localized shear deformation would be generated. The adiabatic shear band is observed in the orthogonal turning of Ti-6Al-4V [34]. In the chip formation process of titanium alloys, the catastrophic adiabatic shear mechanism is proposed by Rechet [35] to describe the segmented chip formation. From a physical ground, Xu et al. [36] discovered the phase transformation effect in the shear band which act as a softening mechanics for the crack propagation. Similar results are also reported in the machining of 340 stainless steel [37].

Since the material flow stress is a strong function of the material microstructure attributes, the material flow stress would have significant change in the machining processes, as shown in Figure 5 [38]. The dominating microstructure factors on material flow stress include grain size, dislocation density and phase composition. Tremendous research has been dedicated to account for the microstructure evolution effect on the machining force. Most of the current research work focuses on the modified Johnson-Cook (JC) flow stress model to include the possible microstructure change in the shear zone. A semi-empirical flow stress model is developed by Guo et al. [39] to capture the dislocation density change in the primary shear zone. In order to explain the obvious strain softening effect at the high speed machining process, Calamaz et al. [40] introduced a TANH (hyperbolic tangent) term into the traditional Johnson-cook flow stress model. A selfconsistent model is proposed by Zhang et al. [41] to account for the phase transformation effect in turning of titanium 
Table 3. Previous research on microstructure sensitive flow stress model.

\begin{tabular}{lc}
\hline References & Model \\
\hline Venkatachalam et al. [42] & $\sigma=\sigma_{0}(\varepsilon, \dot{\varepsilon}, T)+M \alpha G b \sqrt{\frac{k \theta_{a v}}{D_{\text {avg }} b}+K_{h p} D^{-12}}$ \\
Andrade et al. [78] & $\sigma=f(\varepsilon) g(\dot{\varepsilon}) h(T) H(T)$ \\
Calamaz et al. [40] & $\sigma=\left(A+B \varepsilon^{n}\left(\frac{1}{\exp \left(\varepsilon^{a}\right)}\right)\right)\left(1+c \ln \frac{\dot{\varepsilon}}{\varepsilon_{0}}\right)\left[1-\left(\frac{T-T_{r}}{T_{m}-T_{r}}\right)^{m}\right]$ \\
Nemat-Nasser et al. [79] & $\left(D+(1-D) \tanh \left(\frac{1}{(\varepsilon+S)^{c}}\right)\right)$ \\
Zerlli and Armstrong [80] & $\sigma=\sigma_{0} \varepsilon^{n}+\hat{\sigma}\left\{1-\left[-\frac{K}{G_{0} T}\left(\ln \frac{\dot{\varepsilon}}{\varepsilon_{0}}\right)\right]^{1 q}\right\}^{1 p}$ \\
Atmani et al. [46] & $\sigma=C_{0}+C_{1} e^{\left(-C_{3} T+C_{4} T \ln \dot{\varepsilon}\right)}+C_{5} \varepsilon^{n}$ \\
Pan et al. [61] & $\sigma=0.278 \sqrt{d}+\left(\hat{\sigma}-\hat{\sigma}_{a}\right)\left(1-\left[\frac{K T \ln \left(\dot{\varepsilon}_{o s} \dot{e}_{e}^{p}\right)}{g_{0_{\varepsilon}} G b^{3}}\right]^{1 q}\right)^{1 p}$ \\
\hline
\end{tabular}

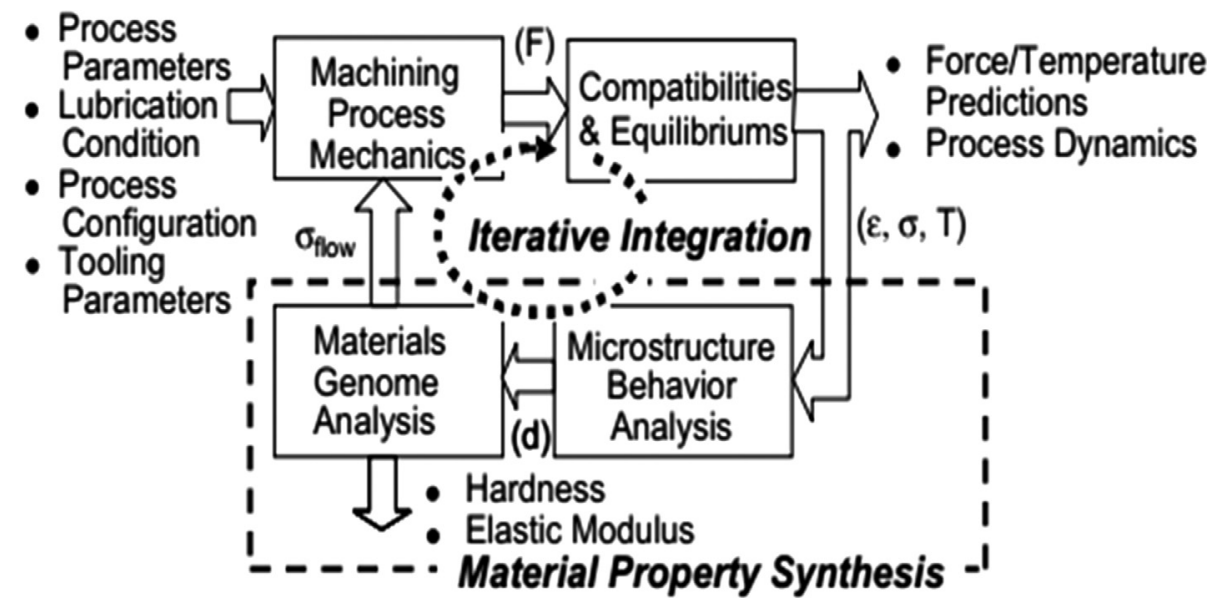

Figure 6. The material microstructure affected machining framework [47].

alloys. An empirical phase transformation model based on the temperature is proposed. The material flow stress is obtained from the simple mixture rule of two different phases. A physics-based continuum flow stress model is proposed by Venkatachalam et al. [42] to account for the grain size and dislocation density effect. However, the grain size evolution model is not explicitly provided. The Johnson-Mehl-Avrami-Kolmogorov model is used for the phase transformation and grain size calculation in the turning of Ti-6Al-4V by Arısoy and Özel [43]. Based on the phase transformation and grain growth model, a modified Johnson-Cook flow stress model is proposed to consider the grain size and phase transformation effect in the machining force calculation [44]. Also, an improved chip morphology prediction is achieved.

In addition to the modified JC models, the mechanical threshold flow stress (MTS) model is a physical thermosviscoplastic model that involves the material dislocation glides. A modified version of the MTS model is proposed by Gourdin and Lassila [45] to incorporate the grain size effect from the Hall-Petch law into the athermal stress term. Most recently, Atmani et al. [46] applied the grain size sensitive MTS model to the application in turning of OFHC copper. Better machining force prediction is found compared with the traditional JC model. Some representative microstructure sensitive flow stress models for the application of machining process are listed in the Table 3. A material microstructure affected machining process modeling framework is proposed by Omar et al. [46]. The model gives a general idea of the microstructure implementation in the machining process. Microstructure attributes such as grain size, phase transformation are included, as shown in Figure 6.

\subsection{Material microstructure effect on surface integrity}

The surface consideration covers a wide range of topics including heterogeneous catalysis, lubrication, adhesion and corrosion. In the manufacturing community, the surface integrity concerns the whole assemblage of the surface structure, including physical, mechanical, metallurgical, chemical and biological states. A series of publications by M'Saoubi et al. [48] laid as pioneering review work for machining induced surface integrity. The emphasis of this work would be focused 
(a)

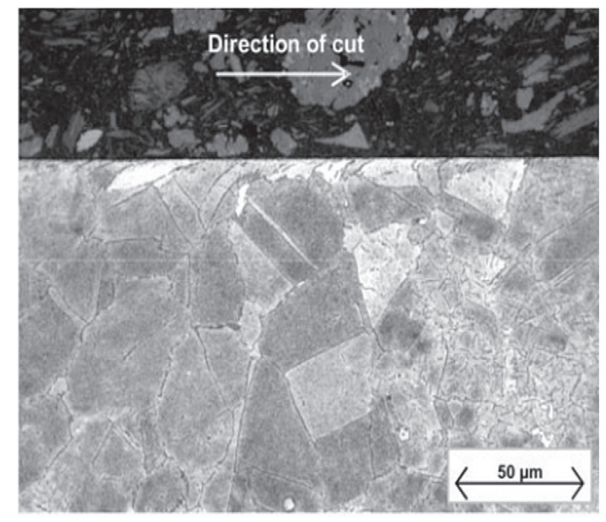

(b)

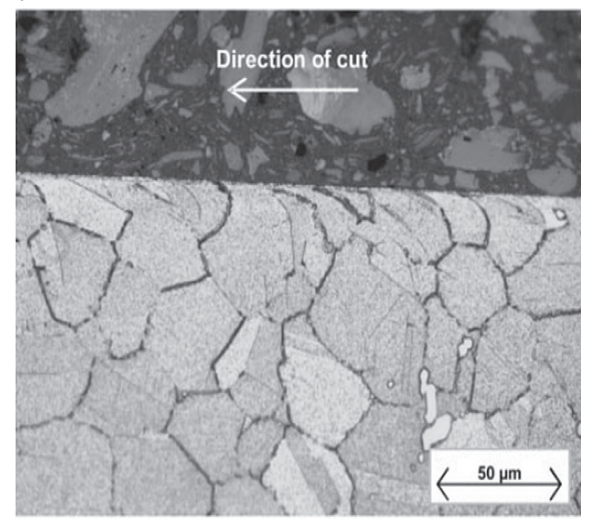

Figure 7. The machined Inconel 718 workpiece subsurface at cutting speed $60 \mathrm{~m} / \mathrm{min}$, feed rate $0.1 \mathrm{~mm} / \mathrm{rev}$, depth of cut $0.5 \mathrm{~mm}$ by a new tool (a) and a worn tool (b) [49].

(a)

$\multimap-V c=125 \mathrm{~m} / \mathrm{min} ; \mathrm{f}=0.05 \mathrm{~mm} / \mathrm{rev} ; \mathrm{ap}=0.50 \mathrm{~mm} ; \mathrm{CW} 1$

- $-V_{c}=125 \mathrm{~m} / \mathrm{min} ; \mathrm{f}=0.05 \mathrm{~mm} / \mathrm{rev} ;$ ap $=0.75 \mathrm{~mm} ; \mathrm{CW} 2$

$\longrightarrow-V_{c}=125 \mathrm{~m} / \mathrm{min} ; \mathrm{f}=0.05 \mathrm{~mm} / \mathrm{rev} ; \mathrm{ap}=1 \mathrm{~mm} ; \mathrm{CH}$

$-x-V c=125 \mathrm{~m} / \mathrm{min} ; \mathrm{f}=0.10 \mathrm{~mm} / \mathrm{rev} ; \mathrm{ap}=0.50 \mathrm{~mm} ; \mathrm{CW} 2$

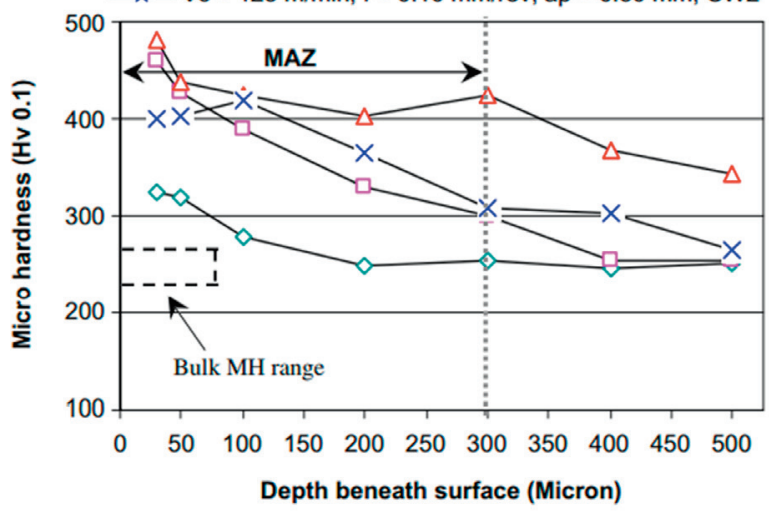

(b)

$\leadsto-V c=125 \mathrm{~m} / \mathrm{min} ; f=0.05 \mathrm{~mm} / \mathrm{rev} ; \mathrm{ap}=0.50 \mathrm{~mm} ; \mathrm{CW} 1$ $\longrightarrow-V c=125 \mathrm{~m} / \mathrm{min} ; \mathrm{f}=0.05 \mathrm{~mm} / \mathrm{rev} ;$ ap $=0.75 \mathrm{~mm} ; \mathrm{CW} 2$ $\longrightarrow \checkmark V_{c}=125 \mathrm{~m} / \mathrm{min} ; \mathrm{f}=0.05 \mathrm{~mm} / \mathrm{rev} ; \mathrm{ap}=0.50 \mathrm{~mm} ; \mathrm{CH}$ $-x-V c=125 \mathrm{~m} / \mathrm{min} ; \mathrm{f}=0.10 \mathrm{~mm} / \mathrm{rev} ; \mathrm{ap}=0.50 \mathrm{~mm}, \mathrm{CW} 2$

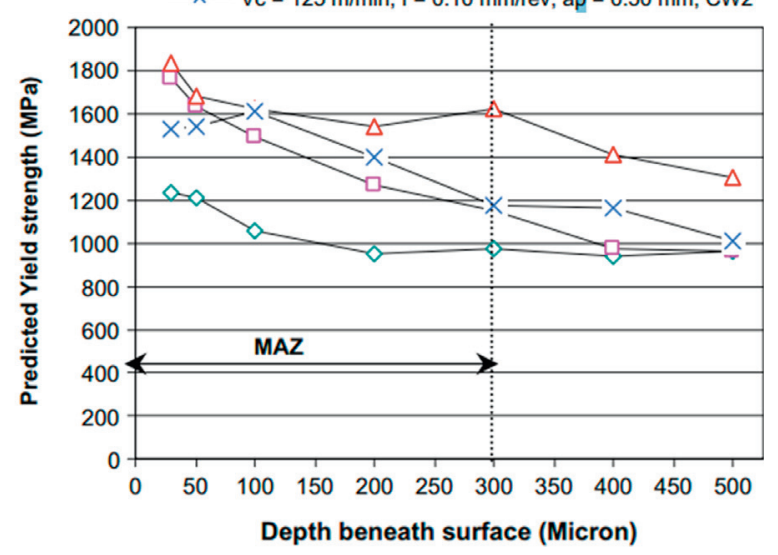

Figure 8. The material microhardness (a) and yield strength (b) as a function of depth into the workpiece at different machining conditions [50].

on the material microstructure alteration in the machining process and how this alteration would affect the machined component surface integrity properties. The surface microstructure alterations are in the form of plastic deformation, micro-cracks, phase transformation, microhardness, recrystallization, tears and residual stress profile. Instead of giving an exhaustive list of the previous related research work, the paper will cover some major issues involved the microstructure structure affected surface integrity in the context of hard to machine material, such as nickel-based alloys and titanium alloys.

\subsubsection{Nickel-based alloys}

The nickel-based alloys retain the mechanical and chemical properties at the high temperature. However, nickel-based alloys are also thermal resistant, which makes considerable heat concentration in the machining processes. As one of the most widely used nickel-based alloys, Inconel 718 is strengthened by the body centred tetragonal $\gamma$ " $-\mathrm{Ni}_{3} \mathrm{Nb}$ precipitates and face centred cubic $\gamma^{\prime}-\mathrm{Ni}_{3}(\mathrm{Al}, \mathrm{Ti})$ precipitates. The high yield strength of the material mainly attributes to the high volume fraction of the $\gamma^{\prime \prime}$ and $\gamma^{\prime}$ strengthening precipitates. The morphology and distribution of the precipitates could be determined by different heat treatment method. The $\gamma$ and grain size is controlled by the cooling rates in the heat treatment. The complicated chemical composition and intermetallic phase transformation phenomenon imposes great challenge for the microstructural investigation. The surface integrity issue concerned with the machining of Inconel 718 includes tensile residual stress, micro-hardness, metallurgical alteration and plastic deformation.

The inhomogeneous grain size distribution is found on the machined subsurface in the dry cutting condition, as shown in Figure 7 [49]. The elongate grain morphology and a directional orientation of the grain boundary point to the cutting direction are observed. More distorted grain morphology is found on the subsurface by the worn tool where significant rubbing occurs. This microstructure alternated layer would typically contribute 
(a)

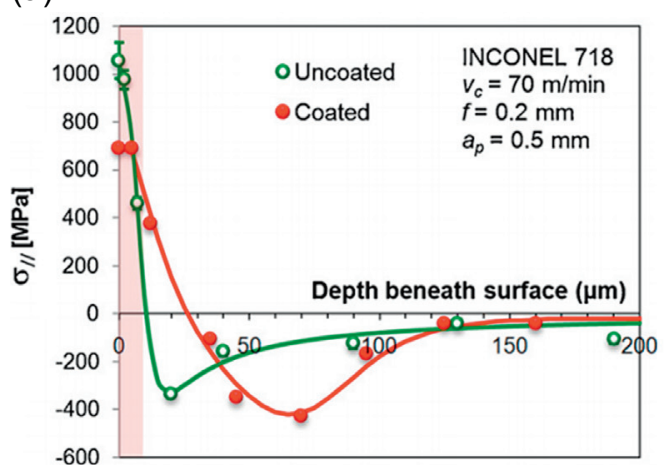

(b)

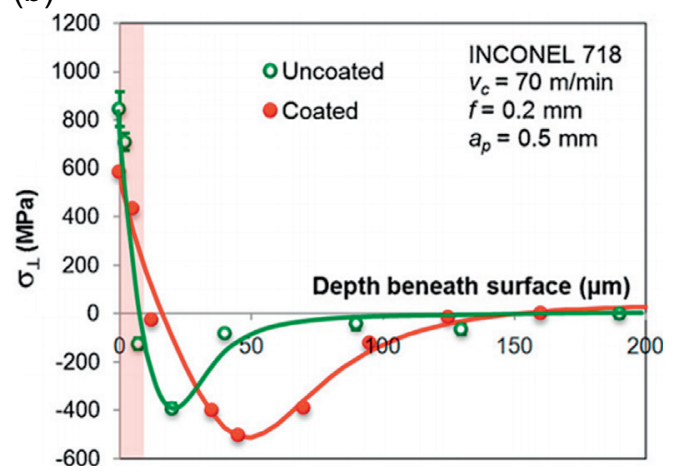

Figure 9. The residual stress profile as a function of depth into the Inconel 718 workpiece in (a) cutting direction and (b) radial direction at cutting speed of $70 \mathrm{~m} / \mathrm{min}$, feed rate $0.2 \mathrm{~mm} / \mathrm{rev}$, depth of cut $0.5 \mathrm{~mm}$ [53].

to the bad surface roughness. However, due to the server plastic deformation, significant strain hardening occurs, which result in the increased micro-hardness of the machined surface. The machined subsurface microhardness is plotted as shown in Figure 8a [50]. The hardness value gradually decreases when the depth into the workpiece increases. The effect of feed rate and depth of cut on the subsurface microstructure are also investigated in Figure 8a. It is interesting to find that, with the increasing depth of cut, the material hardness would slight increase due to the more sever hardening effect. An empirical prediction model is also proposed to calculate the subsurface material yield stress from the microhadness, as shown in Figure $8 b$.

Large tensile residual stress on the machined surface of Inconel 718 is reported in previous literature work. Arunachalam et al. [51] concluded that the ceramic cutting tool would contribute to large tensile residual stress in the cutting direction compared with CBN tool in the hard turning of Inconel 718. Also the uniformly deformed plastic deformation layer is found in the machined surface of CBN tool, which indicates the possible residual stress release in uniform plastic deformation process. Compared with new cutting tool, the worn tool tends to induce server plastic deformation near the surface area from the ploughing effect [52]. This high level of strain hardening and grain distortion would result in the increased magnitude of tensile residual stress. Similar trend is also found by Outeiro et al. [53]. Comparing the residual stress distribution of the machined surface between coated and TiAlN coated cutting inserts, obvious decrease in the magnitude of tensile residual stress is observed from the TiAlN coated tool, as shown in Figure 9. This could be explained by the less friction between the workpiece and tool, which help to decrease the plastic deformation. Also, with appropriate lubrication and cooling, the magnitude of tensile residual stress could also be reduced, as shown by Devillez et al. [49]. However, the machined surface roughness shows a better qualify in the dry cutting condition than a wet cutting, as shown in Figure 10.

In a typical machining process, the surface roughness is dominated by the feed rate. The residual stress is a combined effect of uniform plastic deformation, temperature gradient and the phase transformation induced volume change.

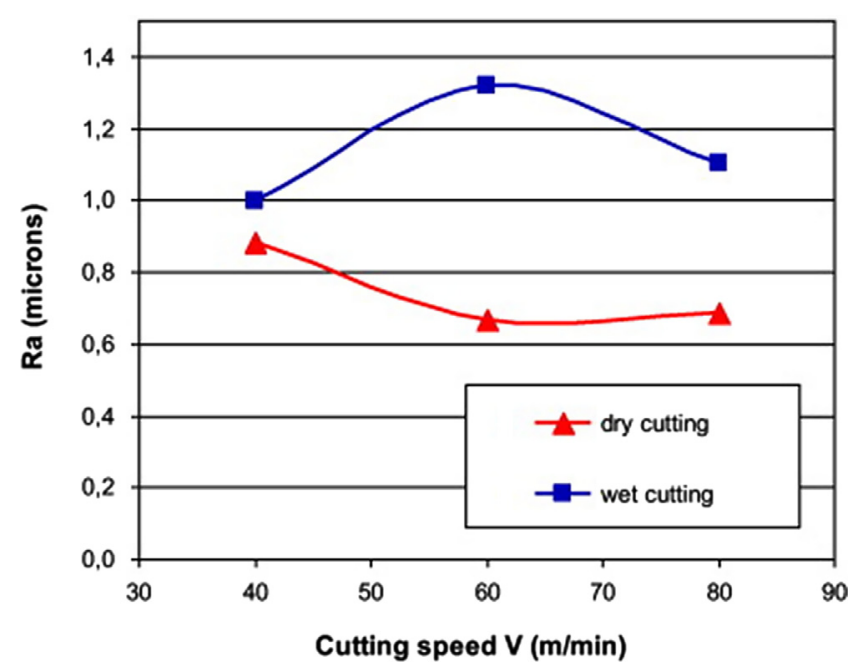

Figure 10. The surface roughness comparison in dry and wet cutting at different cutting speed, with a feed rate of $0.1 \mathrm{~mm} / \mathrm{rev}$, depth of cut $0.5 \mathrm{~mm}$ [49].

Previous research work shows interesting observations on these topics. With the increasing cutting speed, the surface roughness value would be larger. The surface residual stress in the cutting direction would become more tensile, as reported by Arunachalam et al. [51]. In a similar study by Thakur et al. [54], the surface roughness improves with the increasing cutting speed. However, in the separate study by Devillez [49], the residual stress is reported to be more compressive with the increasing cutting speed.

The chip morphology is dominated by the fracture initiation and propagation in the chip. The material fracture initiation is dependent on the strain, strain rate and temperature. Additionally, the material microstructure evolution, especially the phase transformation, could promote the material ductile to brittle transition in the shear zone. This ductile to brittle transition would also promote the crack initiation and result in the segmented chip morphology. In the machining of Inconel 718, the critical machining speed for chip segmentation is found to be around $50 \mathrm{~m} / \mathrm{min}$, above which the saw 
(a)

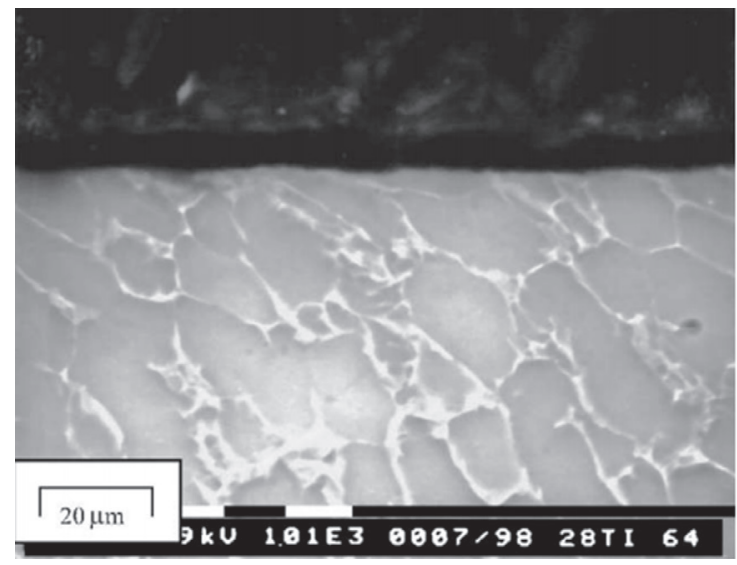

(b)

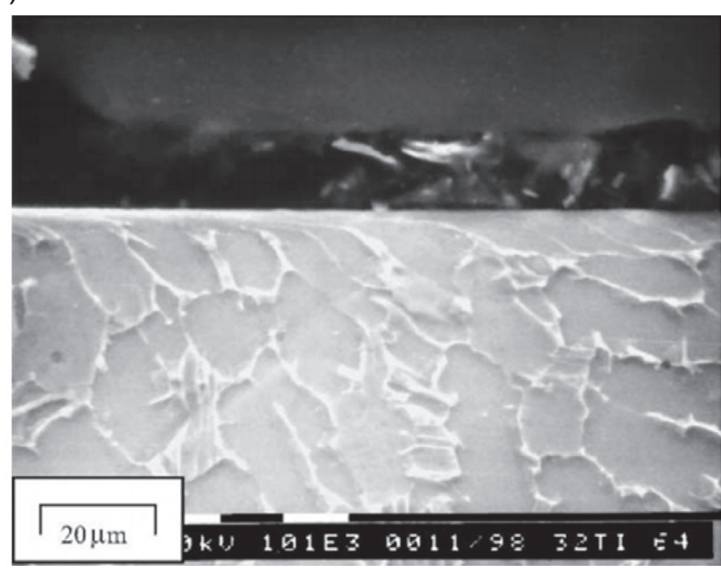

Figure 11. Machined surfaced of Ti-6Al-4V with a new tool (a), and with a worn out tool (b) [58].

tooth chip would be formed. As reported by Pawade and Joshi [55], segmented chip formation in machining of Inconel 718 would increase the surface roughness value. Further study shows that, the localize shear band in the chip, which elongated grain size occurs, also contributes the segmented chip. Therefore, both the phase transformation effect and grain size growth in the shear zone would result in the segmented chip, which increases the surface roughness value.

\subsubsection{Titanium alloys}

Titanium alloys could be divided into three types based on the crystal structure, $\alpha$ alloys, $\beta$ alloys and $\alpha+\beta$ alloys. The $\alpha$ alloys have $\alpha$ stabilizer such as aluminum and tin with hep structure at the room temperature. High strength, toughness are the main characters of $\alpha$ alloys. The $\beta$ alloys are in the state of bcc phase which contains large amount of $\beta$ isomorphous additions, such as vanadium, niobium and tantalum. The low strength characterizes the basic mechanical property of the $\beta$ alloys. For the $\alpha+\beta$ alloys, more than one $\alpha$ stabilizers together with $\beta$ stabilizers exist. The dominating factor that influences titanium alloy mechanical properties is the $\alpha$ phase colony size. The yield strength, fracture toughness and ductility could be greatly improved by reducing the colony size of $\alpha$ phase.

A so called coating delamination phenomenon is observed by Ginting and Nouari [56] in the machining of Ti-6242S, which the coating layer peels off and deposit on the major cutting edge. This delamination effect results in the poor surface roughness. A comprehensive surface roughness investigation is conducted by Sun and Guo [57] in the end milling of Ti-6Al-4V. The surface roughness value increases with the increasing cutting speed up to $80 \mathrm{~m} / \mathrm{min}$, and then decreases with the further cutting speed increase. A $70 \mu \mathrm{m}$ thick hardened layer below the machined surface is reported by Che-Haron and Jawaid [58] in the dry turning of Ti-6Al-4V. More obvious hardening effect is found with a worn cutting insert, as similar with the Inconel 718. This microhardness improve could be attributed to the strain hardening in the plas- tic deformation process. More uniformly distributed plastic deformation layer is found at a higher cutting speed. With a worn insert, the rubbing effect is more significant. Irregular grain morphology is reported, as shown in Figure 11. The machined surface microhardness is reported by Ginting and Nouari [56], as shown in Figure 12. The micro-hardness improvement could be also due to the dynamic recrystallization process where grain refinement occurs. However, different from the Inconel 718, the large hardness value is not on the machined surface. The hardness value gradually increase from the machined surface, around $100 \mu \mathrm{m}$ beneath the surface, the maximum value is achieved. When the depth into the workpiece further increases, the micro-hardness slight decrease. The hardness affected zone is around $350 \mu \mathrm{m}$. In a separate work of Sharman et al. [59] for the finish turning of gamma titanium aluminide, the maximum microhardness value is found on the machined surface rather than beneath the surface. This could be explained by the possible phase transformation or softening effect in Ginting's work where the depth of cut is larger than a finish turning. It is validated from the ball end milling of Ti-6Al-4V by Mhamdi et al. [60], in which the depth of milling is only $0.5 \mathrm{~mm}$. In the different study, Pan et al. [61] reported that, the smallest grain size value is found on the machined workpiece surface in the orthogonal turning of Ti-6Al-4V, which indicates the largest hardness value. So, in the machining process with a smaller cutting depth, the machined surface have the most significant hardening effect. In a more aggressive machining, the hardening effect is beneath the surface.

The residual stress in the cutting direction is typically found to be tensile on the machined surface [62]. The magnitude of tensile residual stress sharply decreases with the increasing depth into the workpiece. The material microstructure alteration and temperature effects are believed to be the dominating factors that influence the residual stress distribution on the machined surface. The higher cutting speed will help to increase the cutting temperature. A comprehensive study is conducted by Sun and Guo [57] in the end milling of Ti-6Al-4V material, as shown in Figure 13. It is found that 


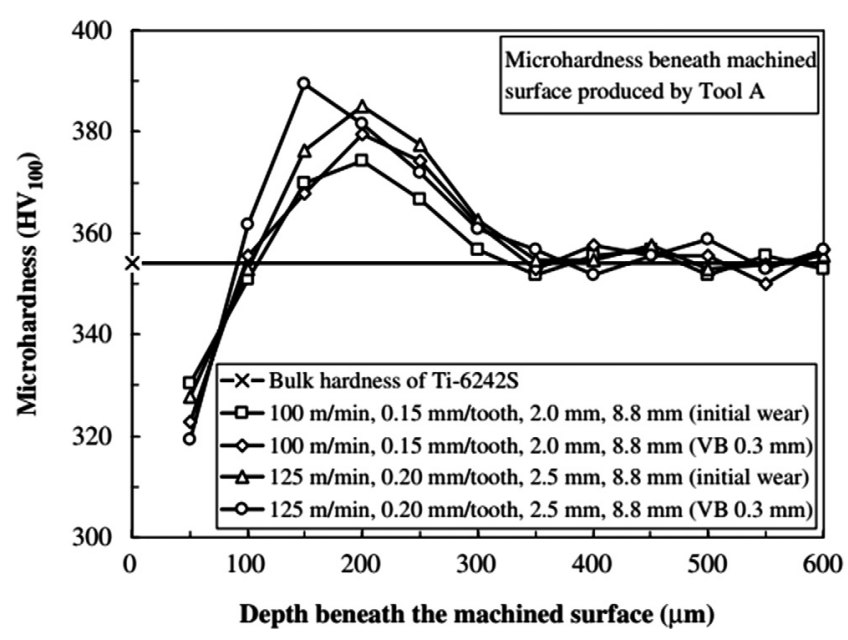

Figure 12. The micro-hardness value as a function of depth into the Ti-6242S workpiece at different cutting condition [56].

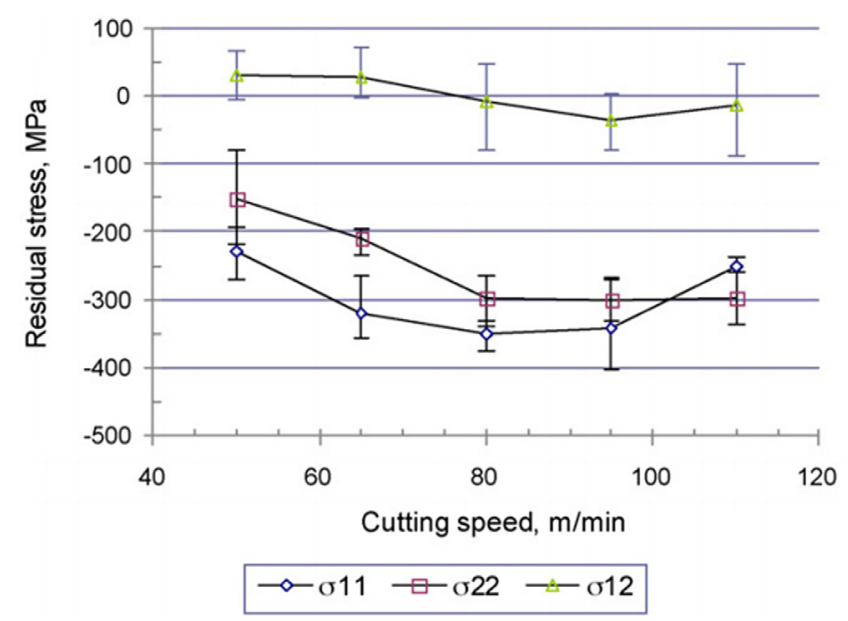

Figure 13. The effect of cutting speed on the surface residual stress at feed rate $0.08 \mathrm{~mm} /$ tooth, radial depth of cut $4 \mathrm{~mm}$, axial depth of cut $1.5 \mathrm{~mm}$ [57].

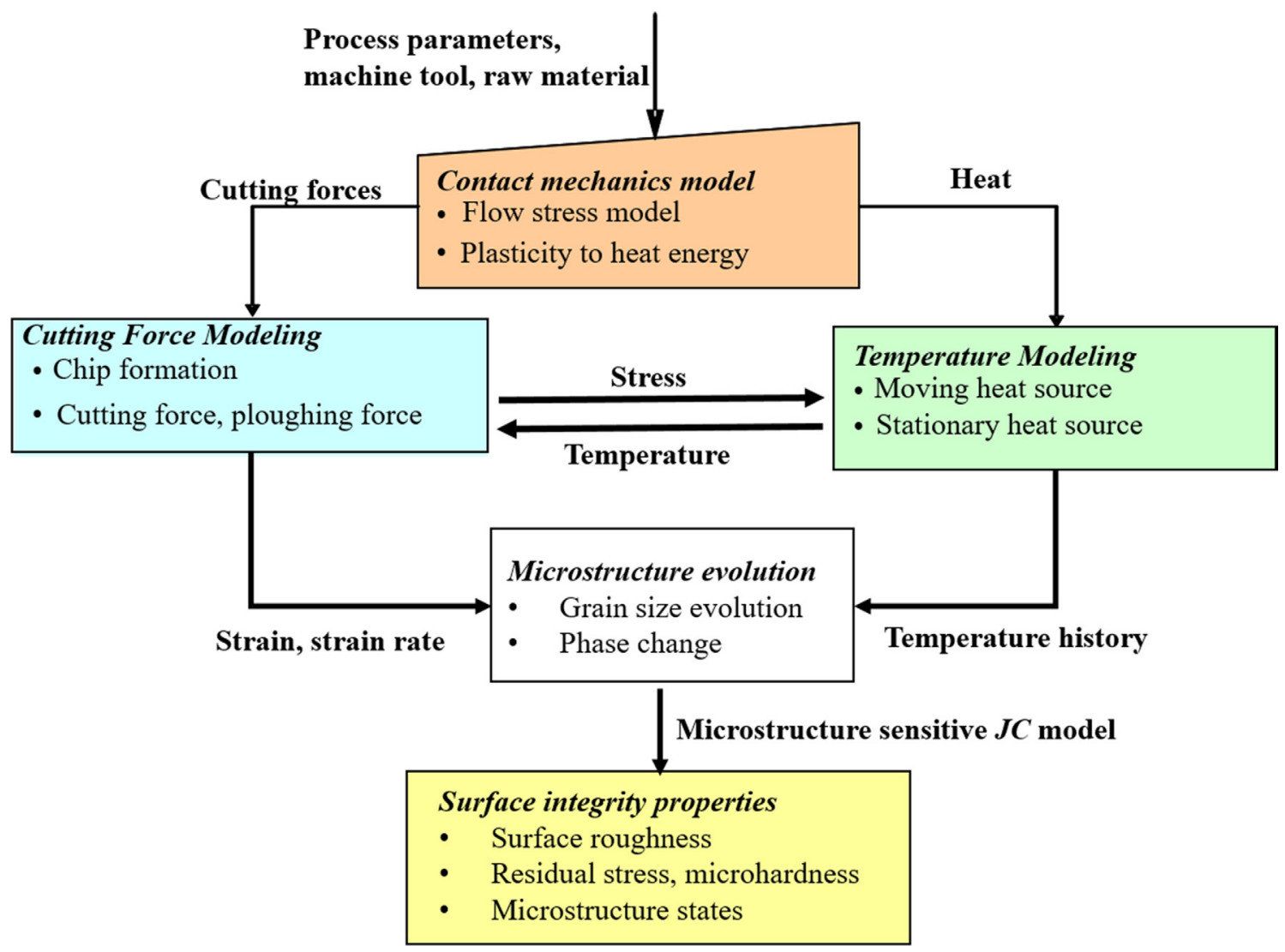

Figure 14. Material microstructure affected machining implementation framework (adapted from [44]).

the magnitude of residual stress in all three direction would slightly increase with the increasing cutting speed. The normal residual stress is almost negligible compared with the other two directions, which indicates large shear deformation on the machined surface. Through appropriate control of the machining process parameters, the residual stress on the machined surface of Ti-6Al-4V could be altered to compressive as reported by Daymi et al. [63].

\section{Conclusion}

The detailed implementation of the material microstructure affected machining modeling framework is summarized in Figure 14. The model takes the material properties, machine tool configuration and process parameters into consideration. The direct output could be machine tool related tool wear, material removal rate, and the end-product surface integrity 
properties, such as residual stress, microstructure states, surface roughness, and microhardness. The empirical model is capable of the machining induced microstructure evolution prediction based on extensive experimental data, where the regression analysis could be conducted to establish this relationship. However, this empirical model suffers from the inflexibility, which requires repeated experimental data given any slight change on the machining conditions or material system. Staring from the basic mechanics and microstructure evolution principles, the physical model could serve as an universal modelling method. The physical based model which quantitatively calculates the microstructure evolution in the machining process has been numerically implemented for the grain size and phase transformation calculation. Challenges still exist in terms of more microstructure attributes inclusion, such as dislocation density, texture information. Complicated material system, such as steel alloys, requires more comprehensive model. The physical based model bears more physical meanings which provide the insights on the material microstructure, mechanics and thermal interactions in the machining process.

The material microstructure property is an important consideration in the machining process. Both the material mechanical properties and machined surface integrity are directly related to the material microstructure attributes. The manuscript reviews the recent development of machining process with a material microstructural consideration. A comprehensive computational modeling framework could be developed to predict the machined part microstructural related properties by taking the cutting parameters, machine tool configuration and raw material selection as the input. On the other hand, given the part application with a specific material microstructure requirement, a reverse modeling approach would be necessary to trace back to all possible combinations of the process parameters, raw material selection and machining tool configuration. Previous machining process optimization work mainly focuses on the design of experimental based regression analysis. The current work aims to review the machining process modeling approach with material microstructure consideration, and point out some useful guidelines for the physical based inverse modeling method for the machining process design. This review paper gives an overview of the machining induced material microstructure change. The following conclusions are given in the review.

- The machining induced microstructure change on the machined workpiece surface typically manifest as the white layer. The white layer generation is a combined effect of high temperature, stress and strain.

- The microstructure evolution in the primary shear zone includes elongated grain structure and phase transformation. The chip morphology dominated by the phase transformation and micro-crack propagation in the shear zone.

- The microstructure change in the shear zone is typically modeled as strain softening or high temperature softening, which will help to reduce the machining forces.

- Modified JC model and MTS models are developed to include the microstructure attributes (grain size, dislocation, phase composition) in the material flow stress model.
- The machined surface integrity affected by the microstructure properties covers residual stress, microhardness, roughness.

- Refined grains and increased microhardness are found on the machined surface due to machining induced microstructure change.

- The residual stress profiles are influenced by machining process parameters. The stress free surface could be generated by appropriate selection of machining process parameters.

\section{References}

1. C. Yue, X. Liu, S.Y. Liang, A model for predicting chatter stability considering contact characteristic between milling cutter and workpiece, The International Journal of Advanced Manufacturing Technology 88 (2016) 2345-2354.

2. X. Lu, et al., Tool wear appearance and failure mechanism of coated carbide tools in micro-milling of Inconel 718 super alloy, Industrial Lubrication and Tribology 68 (2016) 267-277.

3. Z. Pan, et al., Analytical model for force prediction in laserassisted milling of IN718, The International Journal of Advanced Manufacturingg Technology (2016), DOI: 10.1007/ s00170-016-9629-6.

4. C.F. Cheung, W.B. Lee, A multi-spectrum analysis of surface roughness formation in ultra-precision machining, Precision Engineering 24 (2000) 77-87.

5. S. Zhang, et al., A review of surface roughness generation in ultra-precision machining, International Journal of Machine Tools and Manufacture 91 (2015) 76-95.

6. J.P. Davim, Surface integrity in machining, Springer, London, 2010, ISBN: 1848828742.

7. C. $\mathrm{Wu}$, et al., Prediction of grinding force for brittle materials considering co-existing of ductility and brittleness, The International Journal of Advanced Manufacturing Technology 87 (2016) 1967-1975.

8. D. Ulutan, T. Ozel, Machining induced surface integrity in titanium and nickel alloys: a review, International Journal of Machine Tools and Manufacture 51 (2011) 250-280.

9. E. Ezugwu, S. Tang, Surface abuse when machining cast iron (G-17) and nickel-base superalloy (Inconel 718) with ceramic tools, Journal of Materials Processing Technology 55 (1995) 63-69.

10. B. Baufeld, O. Van der Biest, R. Gault, Additive manufacturing of Ti-6Al-4V components by shaped metal deposition: microstructure and mechanical properties, Materials \& Design 31 (2010) S106-S111.

11. B. Baufeld, E. Brandl, O. Van der Biest, Wire based additive layer manufacturing: comparison of microstructure and mechanical properties of Ti-6Al-4V components fabricated by laser-beam deposition and shaped metal deposition, Journal of Materials Processing Technology 211 (2011) $1146-1158$.

12. L. Thijs, et al., A study of the microstructural evolution during selective laser melting of Ti-6Al-4V, Acta Materialia 58 (2010) 3303-3312.

13. Y.K. Chou, C.J. Evans, White layers and thermal modeling of hard turned surfaces, International Journal of Machine Tools and Manufacture 39 (1999) 1863-1881. 
14. D. Araujo, et al., Microstructural study of $\mathrm{CO}_{2}$ laser machined heat affected zone of 2024 aluminum alloy, Applied Surface Science 208 (2003) 210-217.

15. T. El-Wardany, H. Kishawy, M. Elbestawi, Surface integrity of die material in high speed hard machining, part 1: micrographical analysis, Journal of manufacturing science and engineering 122 (2000) 620-631.

16. K.B. Popov, et al., Micromilling: material microstructure effects, Proceedings of the Institution of Mechanical Engineers, Part B: Journal of Engineering Manufacture 220 (2006) 1807-1813.

17. D. Axinte, R. Dewes, Surface integrity of hot work tool steel after high speed milling-experimental data and empirical models, Journal of Materials Processing Technology 127 (2002) 325-335.

18. S. Ghosh, V. Kain, Microstructural changes in AISI 304L stainless steel due to surface machining: effect on its susceptibility to chloride stress corrosion cracking, Journal of Nuclear Materials 403 (2010) 62-67.

19. S. Ranganath, C. Guo, P. Hegde, A finite element modeling approach to predicting white layer formation in nickel superalloys, CIRP Annals-Manufacturing Technology 58 (2009) 77-80.

20. C. Duan, et al., Modeling of white layer thickness in high speed machining of hardened steel based on phase transformation mechanism, The International Journal of Advanced Manufacturing Technology 69 (2013) 59-70.

21. A. Ramesh, S.N. Melkote, Modeling of white layer formation under thermally dominant conditions in orthogonal machining of hardened AISI 52100 steel, International Journal of Machine Tools and Manufacture 48 (2008) 402-414.

22. S. Han, et al., White layer formation due to phase transformation in orthogonal machining of AISI 1045 annealed steel, Materials Science and Engineering: A 488 (2008) 195-204.

23. Y.K. Chou, H. Song, Thermal modeling for white layer predictions in finish hard turning, International Journal of Machine Tools and Manufacture 45 (2005) 481-495.

24. D. Umbrello, et al., Modeling of white and dark layer formation in hard machining of AISI 52100 bearing steel, Machining Science and Technology 14 (2010) 128-147.

25. Z. Wan, et al., Microstructure evolution of adiabatic shear bands and mechanisms of saw-tooth chip formation in machining Ti6Al4V, Materials Science and Engineering: A 531 (2012) 155-163.

26. R. Shivpuri, et al., Microstructure-mechanics interactions in modeling chip segmentation during titanium machining, CIRP Annals-Manufacturing Technology 51 (2002) 71-74.

27. M.P. Vogler, R.E. DeVor, S.G. Kapoor, On the modeling and analysis of machining performance in micro-endmilling, part I: surface generation, Journal of Manufacturing Science and Engineering 126 (2004) 685-694.

28. Z. Pan, et al., Modeling of Ti-6Al-4V machining force considering material microstructure evolution, The International Journal of Advanced Manufacturing Technology (2017) $1-8$.

29. Z. Yuan, L. Geng, S. Dong, Ultraprecision machining of SiCw/ Al composites 11 the project supported by National Natural Science Foundation of China, CIRP Annals-Manufacturing Technology 42 (1993) 107-109.

30. Y. Furukawa, N. Moronuki, Effect of material properties on ultra precise cutting processes, CIRP Annals-Manufacturing Technology 37 (1988) 113-116.
31. Y.K. Chou, Hard turning of M50 steel with different microstructures in continuous and intermittent cutting, Wear 255 (2003) 1388-1394.

32. L. Chuzhoy, R. DeVor, S. Kapoor, D. Bammann, Microstructure-level modeling of ductile iron machining, Journal of Manufacturing Science and Engineering 124 (2002) 162-169.

33. R.E. DeVor, On the modeling and analysis of machining performance in micro-endmilling, part II: cutting force prediction, Urbana 51 (2004) 61801-2906.

34. A. Molinari, C. Musquar, G. Sutter, Adiabatic shear banding in high speed machining of Ti-6Al-4V: experiments and modeling, International Journal of Plasticity 18 (2002) 443-459.

35. R. Recht, Catastrophic thermoplastic shear, Journal of Applied Mechanics 31 (1964) 186-193.

36. Y. Xu, et al., Shear localization in dynamic deformation: microstructural evolution, Metallurgical and Materials Transactions A 39 (2008) 811.

37. M. Meyers, et al., Microstructural evolution in adiabatic shear localization in stainless steel, Acta Materialia 51 (2003) 1307-1325.

38. R. Ebrahimi, E. Shafiei, Mathematical modeling of single peak dynamic recrystallization flow stress curves in metallic alloys, in: K. Sztwiertnia (Ed.), Recrystallization, InTech, 2012, pp. 207-224.

39. Y. Guo, Q. Wen, M. Horstemeyer, An internal state variable plasticity-based approach to determine dynamic loading history effects on material property in manufacturing processes, International Journal of Mechanical Sciences 47 (2005) 1423-1441.

40. M. Calamaz, D. Coupard, F. Girot, A new material model for 2D numerical simulation of serrated chip formation when machining titanium alloy Ti-6Al-4V, International Journal of Machine Tools and Manufacture 48 (2008) 275-288.

41. X. Zhang, R. Shivpuri, A. Srivastava, Role of phase transformation in chip segmentation during high speed machining of dual phase titanium alloys, Journal of Materials Processing Technology 214 (2014) 3048-3066.

42. S. Venkatachalam, et al., Microstructure effects on cutting forces and flow stress in ultra-precision machining of polycrystalline brittle materials, Journal of Manufacturing Science and Engineering 137 (2015) 021020.

43. Y.M. Arısoy, T. Özel, Prediction of machining induced microstructure in Ti-6Al-4V alloy using 3-D FE-based simulations: effects of tool micro-geometry, coating and cutting conditions, Journal of Materials Processing Technology 220 (2015) 1-26.

44. Z. Pan, A. Tabei, D.S. Shih, H. Garmestani, S.Y. Liang, The effects of dynamic evolution of microstructure on machining forces, Proceedings of the Institution of Mechanical Engineers, Part B: Journal of Engineering Manufacture (2017), DOI: 10.1177/0954405417703430.

45. W. Gourdin, D. Lassila, Flow stress of OFE copper at strain rates from $10^{-3}$ to $10^{4} \mathrm{~s}^{-1}$ : grain-size effects and comparison to the mechanical threshold stress model, Acta Metallurgica et Materialia 39 (1991) 2337-2348.

46. Z. Atmani, et al., Multi-physics modelling in machining OFHC copper - coupling of microstructure-based flow stress and grain refinement models, Procedia CIRP 31 (2015) 545-550.

47. O. Fergani, S.Y. Liang, Materials-affected manufacturing, Manufacturing Letters 1 (2013) 74-77.

48. R. M'Saoubi, et al., A review of surface integrity in machining and its impact on functional performance and life of machined products, International Journal of Sustainable Manufacturing 1 (2008) 203-236. 
49. A. Devillez, et al., Dry machining of Inconel 718, workpiece surface integrity, Journal of Materials Processing Technology 211 (2011) 1590-1598.

50. R. Pawade, S.S. Joshi, P. Brahmankar, Effect of machining parameters and cutting edge geometry on surface integrity of high-speed turned Inconel 718, International Journal of Machine Tools and Manufacture 48 (2008) 15-28.

51. R. Arunachalam, M. Mannan, A. Spowage, Residual stress and surface roughness when facing age hardened Inconel 718 with CBN and ceramic cutting tools, International Journal of Machine Tools and Manufacture 44 (2004) 879-887.

52. A. Sharman, J. Hughes, K. Ridgway, An analysis of the residual stresses generated in Inconel $718^{\mathrm{TM}}$ when turning, Journal of Materials Processing Technology 173 (2006) 359-367.

53. J. Outeiro, et al., Analysis of residual stresses induced by dry turning of difficult-to-machine materials, CIRP AnnalsManufacturing Technology 57 (2008) 77-80.

54. D. Thakur, B. Ramamoorthy, L. Vijayaraghavan, Study on the machinability characteristics of superalloy Inconel 718 during high speed turning, Materials \& Design 30 (2009) 1718-1725.

55. R. Pawade, S.S. Joshi, Mechanism of chip formation in highspeed turning of Inconel 718, Machining Science and Technology 15 (2011) 132-152.

56. A. Ginting, M. Nouari, Surface integrity of dry machined titanium alloys, International Journal of Machine Tools and Manufacture 49 (2009) 325-332.

57. J. Sun, Y. Guo, A comprehensive experimental study on surface integrity by end milling Ti-6Al-4V, Journal of Materials Processing Technology 209 (2009) 4036-4042.

58. C. Che-Haron, A. Jawaid, The effect of machining on surface integrity of titanium alloy Ti-6\% Al-4\% V, Journal of Materials Processing Technology 166 (2005) 188-192.

59. A. Sharman, et al., Workpiece surface integrity considerations when finish turning gamma titanium aluminide, Wear 249 (2001) 473-481.

60. M. Mhamdi, et al., Surface integrity of titanium alloy Ti-6Al-4V in ball end milling, Physics Procedia 25 (2012) 355-362.

61. Z. Pan, et al., Prediction of machining-induced phase transformation and grain growth of Ti-6Al-4V alloy, The International Journal of Advanced Manufacturing Technology 87 (2016) 859-866.

62. T. Özel, D. Ulutan, Prediction of machining induced residual stresses in turning of titanium and nickel based alloys with experiments and finite element simulations, CIRP AnnalsManufacturing Technology 61 (2012) 547-550.

63. A. Daymi, et al., Surface integrity in high speed end milling of titanium alloy Ti-6Al-4V, Materials Science and Technology 27 (2011) 387-394.

64. B. Griffiths, White layer formations at machined surfaces and their relationship to white layer formations at worn surfaces, Journal of Tribology (Transactions of the American Society of Mechanical Engineers) 107 (1985) 165-171.
65. A. Barbacki, M. Kawalec, Structural alterations in the surface layer during hard machining, Journal of Materials Processing Technology 64 (1997) 33-39.

66. D. Umbrello, L. Filice, Improving surface integrity in orthogonal machining of hardened AISI 52100 steel by modeling white and dark layers formation, CIRP Annals-Manufacturing Technology 58 (2009) 73-76.

67. G. Poulachon, et al., An experimental investigation of work material microstructure effects on white layer formation in PCBN hard turning, International Journal of Machine Tools and Manufacture 45 (2005) 211-218.

68. J. Barry, G. Byrne, TEM study on the surface white layer in two turned hardened steels, Materials Science and Engineering: A 325 (2002) 356-364.

69. S. Bosheh, P. Mativenga, White layer formation in hard turning of H13 tool steel at high cutting speeds using CBN tooling, International Journal of Machine Tools and Manufacture 46 (2006) 225-233.

70. J.P. Velásquez, et al., Sub-surface and surface analysis of high speed machined Ti-6Al-4V alloy, Materials Science and Engineering: A 527 (2010) 2572-2578.

71. J. Derep, Microstructure transformation induced by adiabatic shearing in armour steel, Acta Metallurgica 35 (1987) 1245-1249.

72. C. Duan, L. Zhang, Adiabatic shear banding in AISI 1045 steel during high speed machining: mechanisms of microstructural evolution, Materials Science and Engineering: A 532 (2012) 111-119.

73. A. Bayoumi, J. Xie, Some metallurgical aspects of chip formation in cutting Ti-6wt.\% Al-4wt.\% V alloy, Materials Science and Engineering: A 190 (1995) 173-180.

74. J.P. Velásquez, et al., Metallurgical study on chips obtained by high speed machining of a Ti-6wt.\% Al-4wt.\% V alloy, Materials Science and Engineering: A 452 (2007) 469-474.

75. G. Ye, et al., Modeling periodic adiabatic shear band evolution during high speed machining Ti-6Al-4V alloy, International Journal of Plasticity 40 (2013) 39-55.

76. C. Campbell, et al., Microstructural characterization of Al-7075-T651 chips and work pieces produced by high-speed machining, Materials Science and Engineering: A 430 (2006) 15-26.

77. M.R. Shankar, et al., Characteristics of aluminum 6061-T6 deformed to large plastic strains by machining, Materials Science and Engineering: A 410 (2005) 364-368.

78. U. Andrade, et al., Dynamic recrystallization in high-strain, high-strain-rate plastic deformation of copper, Acta Metallurgica et Materialia 42 (1994) 3183-3195.

79. S. Nemat-Nasser, et al., Dynamic response of conventional and hot isostatically pressed Ti-6Al-4V alloys: experiments and modeling, Mechanics of Materials 33 (2001) 425-439.

80. F.J. Zerilli, R.W. Armstrong, Dislocation-mechanics-based constitutive relations for material dynamics calculations, Journal of Applied Physics 61 (1987) 1816-1825.

Cite this article as: Pan Z, Feng Y \& Liang SY: Material microstructure affected machining: a review. Manufacturing Rev. 2017, 4, 5. 